EGU2020-19143

https://doi.org/10.5194/egusphere-egu2020-19143

EGU General Assembly 2020

(c) Author(s) 2021. This work is distributed under

the Creative Commons Attribution 4.0 License.

\title{
First observations of the Search Coil Magnetometer on Solar Orbiter / RPW: results and performances
}

Matthieu Kretschmar ${ }^{1}$, Volodya Krasnoselskikh ${ }^{1}$, Jean-Yves Brochot ${ }^{1}$, Guillaume Jannet ${ }^{1}$, Thierry Dudok de Wit ${ }^{1}$, Clara Froment ${ }^{1}$, Milan Maksimovic ${ }^{2}$, Thomas Chust ${ }^{3}$, Olivier Le Contel ${ }^{3}$, Jan Soucek ${ }^{4}$, and David Pisa ${ }^{4}$

'LPC2E, CNRS and University of Orléans, France

${ }^{2}$ LESIA, Paris Observatory, France

${ }^{3}$ LPP, Paris, France

${ }^{4}$ IAP, Praha, Czech Republic

The Search Coil Magnetometer (SCM) onboard Solar Orbiter is part of the Radio and Plasma Waves (RPW) experiment and measures the variations of the magnetic field between $10 \mathrm{~Hz}$ and $50 \mathrm{kHz}$ on three axes and between $1 \mathrm{kHz}$ and $1 \mathrm{MHz}$ in one axis. The SCM is located on the boom of the spacecraft and its signal is processed by the LFR, TDS, and HFR analyzers of the RPW experiment. These measurements are essential for the characterization of waves and turbulence in the solar wind. We will describe the first observations made by the instrument with an emphasis on its performances. 